\title{
Morphological Classification of Corrupted Colonic Crypts in Ulcerative Colitis
}

\author{
CARLOS A. RUBIO ${ }^{1}$ and PETER T. SCHMIDT ${ }^{2}$ \\ ${ }^{1}$ Gastrointestinal and Liver Research Laboratory, Department of Pathology, and ${ }^{2}$ Department of Medicine Solna, \\ Center for Digestive Diseases, Karolinska Institute and University Hospital, Stockholm, Sweden
}

\begin{abstract}
Background/Aim: In ulcerative colitis (UC) the colonic mucosa shows, in addition to a high number of inflammatory cells, crypts with architectural distortions, called corrupted colonic crypts (CCC). Here we classify the histologic repertoire and assess the frequency of CCC in UC. Patients and Methods: Five-hundred and sixteen histologic sections from 29 colectomy specimens with UC (24 having adenocarcinoma and five, high-grade dysplasia, $H G D$ ) were reviewed. Results: The vast majority of the colonic mucosa portrayed countless crypts with normal shapes (CNS) lined with normal epithelium, except for 45 CNS: 28 showed inconclusive-suspected cellular changes (ISCC), and 17, highgrade dysplasia (HGD). CCC were subdivided into four groups: i) Crypts with fission distortions, ii) Crypts with length distortions, iii) Crypts with outline distortions and iv) Crypts with axial polarity distortions. The most frequent CCC group had axial polarity distortions (33.4\%), and the less frequent CCC group, outline distortions $(21.1 \%)(p<0.05)$. No apparent differences in frequency between groups were found in colectomies with HGD/carcinoma, or in colectomies preformed for medically-refractory UC without HGD/carcinoma. Out of the 902 CCC present in the specimens, 343 (38.0\%) displayed ISCC, 186 (20.6\%) HGD, and the remaining 373 (41.4\%) normal epithelium. Hence, of the 203 crypts exhibiting HGD, 186 (91.6\%) were CCC and the remaining 17 (8.4\%) CNS $(p<0.05)$. Conclusion: Based on these findings it is suggested that the microscopic search for HGD in UC colectomyspecimens should preferentially be focused on mucosal areas exhibiting CCC. This view is validated by recent findings
\end{abstract}

This article is freely accessible online.

Correspondence to: Dr. Carlos A. Rubio, Department of Pathology, Karolinska Institute and University Hospital, 17176, Stockholm, Sweden. Tel: +46 851774527, Fax: +46 851774524, e-mail: Carlos.Rubio@ki.se

Key Words: Ulcerative colitis, colonic crypts, architectural distortions, histology, phenotypes. showing that p53 overexpression (a biomarker of epithelial carcinogenesis) significantly correlated with architectural distortions of the crypts in UC.

The normal colonic mucosa is built of a single layer of epithelial cells with inward folds called crypts. Crypts replicate by symmetric fission, beginning at the base of the crypts and proceeding upwards until two identical, individual crypts are created (1). Sections cut perpendicular to the surface epithelium show a characteristic appearance of "row of test tubes" due to tightly packed parallel crypts, "resting" on the muscularis mucosae. A slight variation in the configuration of the crypts and in the space between the crypts may occur, but crypt branching is rare. This architecture is retained throughout the colon, except for innominate grooves (cloverleaf-like crypts connecting to a single lumen) (1). During crypt renewal, stem cells dwelling at the bottom of the crypts, generate amplifying daughter cells that proliferate and differentiate while migrating upwards $(2,3)$.

In ulcerative colitis (UC) the colonic mucosa exhibits, in addition to high numbers of inflammatory cells, crypts with architectural distortions (4). These crypt distortions usually persist both during the protracted chronic-phase and during disease remission, despite decreased inflammation conveyed by treatment.

Architectural crypt irregularities in UC have received various descriptive terms such as ramification of the crypts (5) considerable branching at the base of the crypts (6), crypt bifurcations (7), architectural aberrations (8), architectural crypt distortion (9) and crypt architectural disarray (10), to name some. In this work, crypts with architectural distortions will be referred to as corrupted colonic crypts $(11,12)$.

Nearly 30 years ago, Allen et al. used semi-automatic image analysis to assess the architectural irregularities of colorectal mucosa in UC (13). Subsequently, Hamilton et al. applied morphometry and stereology to evaluate the architectural characteristics of regenerative and of dysplastic colorectal mucosa in ulcerative colitis (14). Using neural networks on a mosaic of pixilated images (without any image analysis or image segmentation) the authors concluded that 

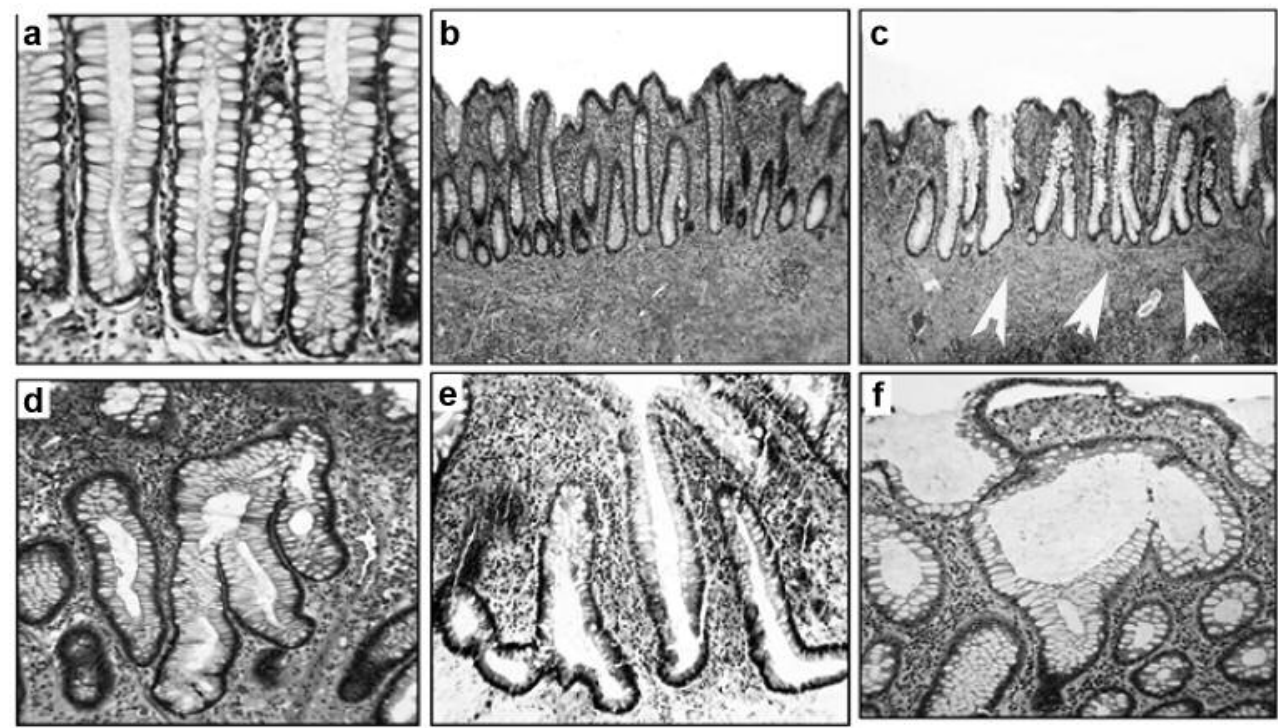

Figure 1. Corrupted colonic crypts with fission distortions (Ulcerative colitis). a: Normal colonic mucosa showing tightly packed, parallel crypts "resting" on the muscularis mucosae, $H \& E \times 20$. b-f: Corrupted colonic crypts with fission distortions (ulcerative colitis) b: Colonic crypts with chronic mucosal inflammation, $H \& E \times 4, c$ : Corrupted colonic crypts with asymmetric fission at arrows. Note expansion of the muscularis mucosa due to chronic inflammation, $H \& E \times 4, d$ : Corrupted colonic crypts with three asymmetric fissions, $H \& E \times 20, e$ : Corrupted colonic crypts showing inverted $T$ and $L$ shapes, $H \& E \times 20$, g: Corrupted colonic crypts with cystic dilatation, $H \& E \times 20)$.

quantitative histological analysis of mucosal abnormalities may be of use in the objective diagnosis of reactive and dysplastic changes in patients with UC (14). More recently, Ficsor et al. (15) reported architectonic irregularities in the colonic mucosa by the aid of automated digital microscopy and advanced digital analysis. Shape-related morphological changes helped to distinguish between normal mucosa and UC. Notwithstanding, the classification of the spectrum of the abnormal shape of the crypts in UC has not been systematically analyzed. In the present work, we classified and assessed the frequency of corrupted colonic crypts (CCC) in a cohort of colectomy specimens from patients with UC.

\section{Patients and Methods}

Archival histological sections from 35 colectomies in patients with UC were reviewed. Six out of the 35 colectomies were rejected from the study: four due to partial mucosal autolysis and the remaining two due to partial faded stainability. In the remaining 29 colectomies, 516 histological sections (mean 17.8, range $=10-42$ sections) were available for study. Sections were cut at $4 \mu \mathrm{m}$ thickness and stained with hematoxylin and eosin (H\&E). Three colectomy-specimens performed because of severe UC, refractory to clinical treatment (without carcinoma or high-grade dysplasia (14) were included as controls.

CCC were subdivided into four groups: i) Crypts with fission distortions, ii) Crypts with length distortions, iii) Crypts with outline distortions, and iv) Crypts with axial polarity distortions (in relationship to the muscular is mucosae).
The epithelial lining in $\mathrm{CCC}$ displayed the following features: a) Normal epithelium, b) Inconclusive or suspected cellular changes (ISCC), ranging from cell regeneration to possibly low-grade dysplasia. CCC lined with ISCC were often seen in areas with chronic- active inflammation, with ulcerated mucosa or with severe chronic inflammation without acute inflammation, c) High-grade dysplasia (HGD) as defined by Riddell et al. (16).

Statistical analysis. The non-parametric Kruskal-Wallis test was applied, to compare difference between groups. Statistical significance was defined as $p<0.05$.

\section{Results}

Clinical data. Gender: Twenty-two were males and the remaining seven, females.

Age: The mean age at colectomy was 48.1 years (range $=32-65$ years).

No. of years with UC prior surgery: The mean number of years with UC prior surgery was 20.7 (range $=10-32$ years).

Histological findings. The histological examination of the 29 colectomy specimens revealed adenocarcinoma in 24 and high-grade dysplasia in the remaining five.

The vast majority of the colonic crypts both in areas with or without chronic inflammation, exhibited normal shapes (CNS) lined with normal epithelium, except from 45 CNS: 28 showing ISCC, and 17, unequivocal high-grade dysplasia (HGD). 

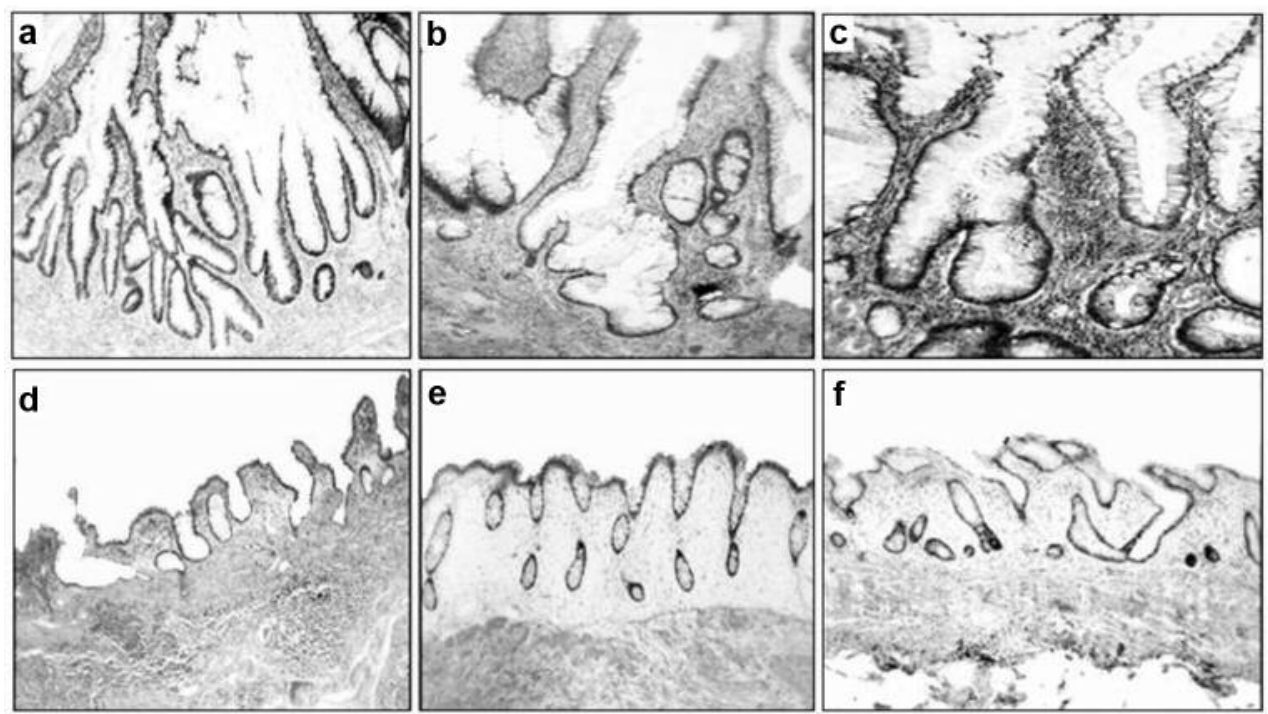

Figure 2. Corrupted colonic crypts with length distortions (ulcerative colitis). a: Two hyperplastic corrupted colonic crypts with multiple asymmetric fissions $(H \& E \times 2), b$ and $c$ : Hyperplastic corrupted colonic crypts, $H \& E \times 4, d$ : Atrophic corrupted colonic crypts, $H \& E \times 2, e-f:$ Atrophic corrupted colonic crypts, $H \& E \times 4$.

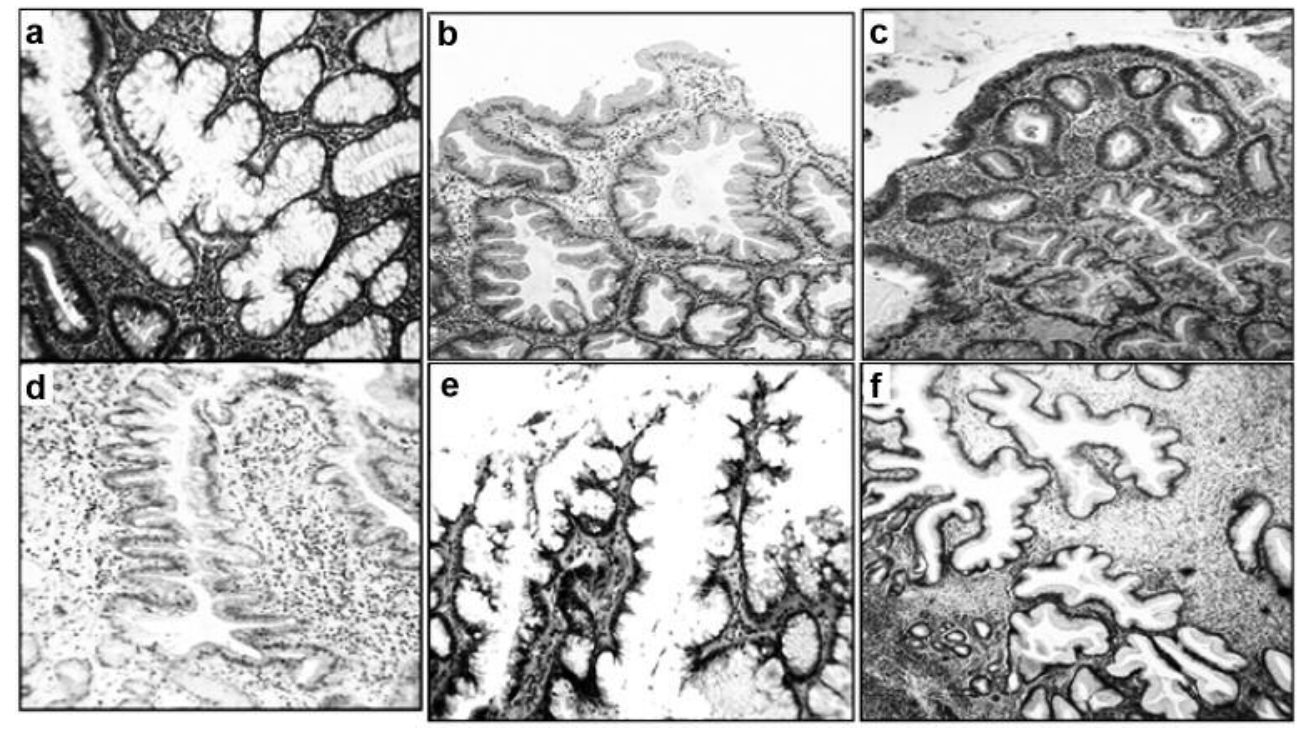

Figure 3. Corrupted colonic crypts with outline distortions (ulcerative colitis). a: Mullti-lobate crypts, H\&E $\times 4$ ), b: Corrupted colonic crypts with serrated architecture, $H \& E \times 4, c$ : Corrupted colonic crypts with serrated architecture, at arrow, $H \& E \times 2, d$ : Detail of corrupted colonic crypt with serrated architecture, $H \& E \times 10$, e-f: Crypts with microtubular-like scalloped borders, $H \& E \times 10$ and $\times 4)$.

The histological evaluation also revealed a total of 902 $\mathrm{CCC}$ in the 29 colectomy specimens (mean 31.1 $\mathrm{CCC} /$ colectomy, range $=22-48 \mathrm{CCC} /$ colectomy). Two or more of the following histologic phenotypes could be found in each group: i) CCC with fission distortions: included asymmetric crypt fissions and cystic crypts (Figure 1), ii) CCC with length distortions: comprised hyperplastic crypts and atrophic crypts (Figure 2), iii) CCC with outline distortions: encompassed mullti-lobate-scalloped crypts, and crypts with: i) serrated outlines, and ii) microtubular outlines (Figure 3), and iv) $\mathrm{CCC}$ with axial polarity distortions in relation to the muscularis mucosae: included meandering-serpentine crypts, 

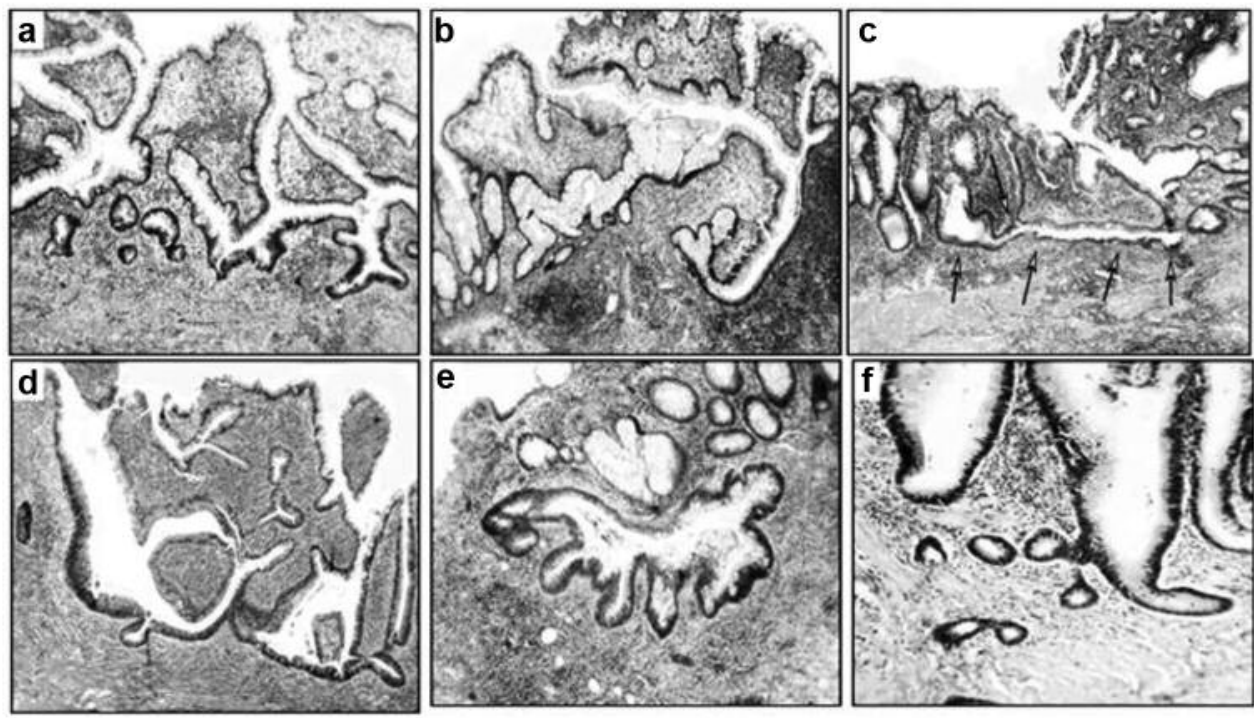

Figure 4. Corrupted colonic crypts with axial polarity distortions, in relation to the muscularis mucosae (ulcerative colitis). a-c: Meanderingintercommunicating crypts, $H \& E \times 4, d$ : Ring-shaped crypts, e: Cystically-dilated crypt with multiple irregular fissions, $f$ : Ring-shaped crypts "rising" in one hyperplasic crypt, $H \& E \times 4$.

Table I. The frequency of histological groups of CCC (corrupted colonic crypts) found in 29 colectomy specimens in patients with ulcerative colitis having carcinoma $(n=24)$, or high-grade dysplasia $(n=5)$. Three additional colectomy specimens performed because of severe UC refractory to clinical treatment (without carcinoma or HGD) are also shown.

Groups of CCC

Colectomies with HGD or Colectomies without HGD or carcinoma (no. 29)

No. CCC

$(\%)$

i) $\mathrm{CCC}$ with fission distortions

ii) $\mathrm{CCC}$ with length distortions

iii) $\mathrm{CCC}$ with outlines distortions

iv) CCC with axial polarity distortions (in relationship to the muscularis mucosae)

$\begin{array}{ll}242(26.8 \%) & 20(28.6 \%) \\ 190(21.1 \%) & 16(22.9 \%) \\ 169(18.7 \%) & 14(20.0 \%) \\ 301(33.4 \%) & 20(28.6 \%)\end{array}$

$902(100 \%)$ carcinoma (no. 3)

No. CCC

(\%)

$20(28.6 \%)$

$14(20.0 \%)$

$(28.6 \%$ inter communicating crypts, ring-shaped crypts, inverted L shapes and horizontal ring-shaped crypts (Figure 4).

The most frequent CCC-group (33.4\%) portrayed crypt axial-polarity distortions (in relationship to the muscular is mucosae), and the less frequent CCC-group (18.7\%), cryptoutline distortions $(p<0.05)$ (Table I).

Epithelial lining in CCC. Out of a total of 902 CCC, 373 (41.4\%) had normal epithelial lining, 343 (38.0\%) inconclusive or suspected cellular changes (ISCA) and the remaining 186 (20.6\%), HGD (Figure 5). CCC with normal epithelium/ISCA $v s$. HGD, $p<0.05)$. Out of the 203 colonic crypts with HGD $186(91.6 \%)$ occurred in CCC and the remaining $178(4 \%)$ in CNS/ISCC $(p<0.05)$.

\section{Discussion}

A systematic analysis of the spectrum of the colonic crypts with abnormal configurations, called CCC, was carried out in colectomy specimens with UC. The scrutiny revealed a high number of $\mathrm{CCC}$ exhibiting a wide range of architectural phenotypes. Rationally, the crypts with ornamentation distortions were generated by the chronic inflammation. And yet, large mucosal areas with chronic inflammation in the specimens had none to occasional CCC. In similarity with these findings, none to occasional CCC were found in a variety of colonic diseases with chronic inflammation such as diverticular disease-associated colitis (17), diversion colitis (18), lymphocytic colitis (19), radiation colitis (20), 


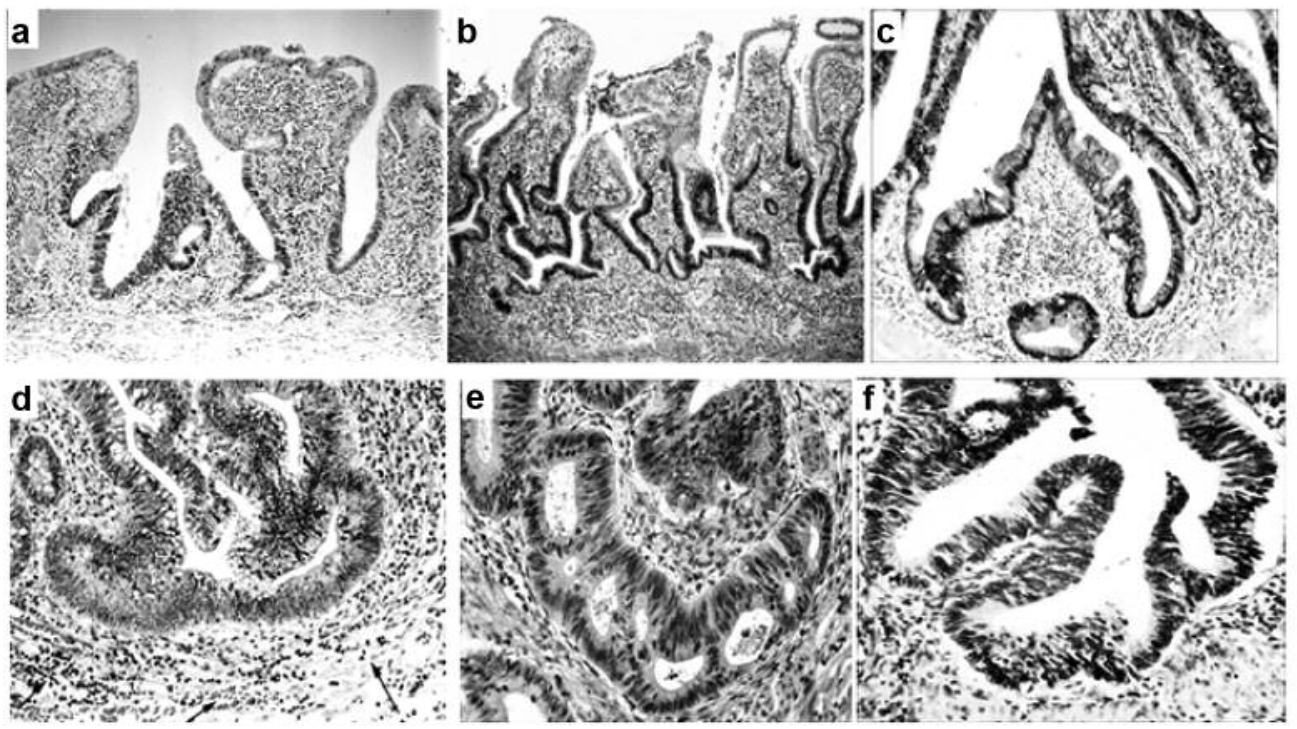

Figure 5. Corrupted colonic crypts with high-grade dysplasia (ulcerative colitis). $a, b: H \& E \times 4, c: H \& E x 4, d-f: \times 20$.

collagenous colitis (21), ischemic colitis (22), chronic colitis in Behçet's disease (23) and non-specific ulcers of the colon (24). A rational explanation for these findings might be that the $\mathrm{CCC}$ in UC might have been generated by factors other than ongoing chronic mucosal inflammation. One possible candidate might be abnormal mucosal regeneration in areas with formerly mucosal denudation. In this context, CCC were recently found in mucosal areas bordering regenerating UC ulcers (11). Why the process of mucosal regeneration severely alters the normal architecture of the colonic crypts surrounding ulcers in colitic patients, remains enigmatic. Nevertheless, since chronic mucosal inflammation per se might not be crucial for the development of CCC (17-24), we are prone to speculate that the $\mathrm{CCC}$ found in the non-ulcerated colonic mucosa in UC could represent abnormal crypt regeneration in areas with formerly mucosal ulcerations in colitic patients (11).

The significance of ISCA, often found in CCC in UC, remains challenging. This since McKenna and Appelman (25) postulated that the category 'indefinite for dysplasia' is an honest recognition of the difficulties in distinguishing reactive or regenerative epithelium from low-grade dysplasia. Moreover, studying inter-observer variation between pathologists regarding the degree of dysplasia in UC, Eaden et al. (26) found total concordance of the 13 pathologists in only four of the 51 slides. Agreement was best for high-grade dysplasia. Based on those findings we opted for classifying crypts with regenerative, 'indefinite for dysplasia' or lowgrade dysplasia (25) as with ISCC, and those with HGD (the histological phenotype less amenable to diagnostic disagreement) (26). In conventional colonic adenomas, HGD initially develops at the luminal aspect of the crypts and progress downwards, towards the base of the crypts (27).

In UC, in contrast, dysplasia initially develops at the base of the crypts and progresses upwards, towards the luminal aspect of the crypts (28). In CCC, we found normal epithelial lining in $>40 \%$, ISCC in $38 \%$ and HGD in $>20 \%$. The finding that HGD was often found in the lower aspect of the CCC is in concert with the "bottom-up" replacement of the crypts by upgrowing dysplastic cells in UC (28). It has been suggested that the CCC might act as scaffolds at the time of "bottom-up" replacement by up-growing mutated dysplastic cells, a notion previously advanced for carcinogen-induced conventional adenomas in experimental animals (12). The same crypt replacement by dysplastic cells may apply to serrated adenomas and microtubular adenomas, inasmuch as CCC with serrated and microtubular configurations lined by normal epithelium occurs in patients with UC (cfr. Figure 3) (29-33).

One possible practical implication of the present findings might be that the microscopic search for HGD in UCcolectomies should primarily be focused on mucosal areas exhibiting CCC. This notion is validated by recent findings by Popp et al. (34) showing that p53 overexpression (a biomarker of epithelial carcinogenesis) significantly correlated with architectural distortions of the crypts in UC (34). The results of Popp et al. (34) seem to be in concert with the our findings, inasmuch as HGD in UC was mainly found in CCC.

In closing, while cellular descriptions and molecular signals that control cell proliferation and cell mutations during carcinogenesis in UC have received much attention 
(35-40), the signals that might be instrumental in designing morphogenesis (41) resulting in the "etching" of various CCC phenotypes in UC, have remained unattended.

\section{References}

1 Levine D and Haggitt RC: Histology for pathologists. Stephen Sternberg (ed.). Raven Press, New York, USA, 1992.

2 Davies JM, Santaolalla R and Abreu MT: Use of cancer stem cells to investigate the pathogenesis of colitis-associated cancer. Inflamm Bowel Dis 22: 976-983, 2016.

3 Rubio CA: Putative stem cells in mucosas of the esophagogastrointestinal tract. Chapter 10. In: Stem cell, regenerative medicine and cancer. Shree Ram Singh (ed.). Nova Science Publishers, Inc, pp. 279-308, 2010.

4 Villanacci V, Antonelli E, Geboes K, Casella G and Bassotti G: Histological healing in inflammatory bowel disease: a still unfulfilled promise. World J Gastroenterol 19: 968-978, 2013.

5 Bressenot A, Cahn V, Danese S and Peyrin-Biroulet L: Microscopic features of colorectal neoplasia in inflammatory bowel diseases. World J Gastroenterolol 20: 3164-3172, 2014.

6 GlickmanJN, Bousvaros A, Farraye FA, Zholudev A, Friedman S, Wang HH, Leichtner AM and Odze RD: Pediatric patients with untreated ulcerative colitis may present initially with unusual morphologic findings. Am J Surg Pathol 28: 190-197, 2004.

7 Pontte AC, Damião AO and Rosa AM: Consensus guidelines for the management of inflammatory bowel disease. Arq Gastroenterol 47: 313-325, 2010.

8 Christensen B, Hanauer SB, Erlich J, Kassim O, Gibson PR, Turner JR, Hart J and Rubin DT: Histologic normalization occurs in ulcerative colitis and is associated with improved clinical outcomes. Clin Gastroenterol Hepatol 15: 1557-1564, 2017.

9 Park S, Abdi T, Gentry M and Laine L: histological disease activity as a predictor of clinical relapse among patients with ulcerative colitis: systematic review and meta-analysis. Am J Gastroenterol 111: 1692-1701, 2016.

10 Goldstein NS and Cinenza AN: The histopathology of nonsteroidal anti-inflammatory drug-associated colitis. Am J Clin Pathol 110: 622-628, 1998.

11 Rubio CA: Corrupted colonic crypts bordering regenerating mucosal ulcers in ulcerative colitis. In Vivo 31: 669-671, 2017.

12 Rubio CA: Corrupted colonic crypt fission in carcinogen-treated rats. PLoS One 12: e0172824, 2017.

13 Allen DC, Hamilton PW, Watt PC and Biggart JD: Architectural morphometry in ulcerative colitis with dysplasia. Histopathology 12: 611-621, 1988.

14 Hamilton PW, Bartels PH, Thompson D, Anderson NH, Montironi R and Sloan JM: Automated location of dysplastic field in colorectal histology using image texture analysis. J Pathol 182: 68-75, 1997.

15 Ficsor L, Varga VS, Tagscherer A, Tulassay and Mollnar B: Automated classification of inflammation in colon histological sections based on digital microscopy and advanced image analysis. Cytometry 73: 230-237, 2008.

16 Riddell RH, Goldman H, Ransohoff DF, Appelman HD, Fenoglio CM, Haggitt RC, Ahren C, Correa P, Hamilton SR and Morson BC: Dysplasia in inflammatory bowel disease: standardized classification with provisional clinical applications. Hum Pathol 14: 931-968, 1983.
17 Ludeman L, Warren BF and Shepherd NA: The pathology of diverticular disease. Best Pract Res Clin Gastroenterol 16: 543562, 2002.

18 Rubio CA, Ásmundsson J, Silva P, Illies C, Hartman J and Kis L: Lymphoid aggregates in Crohn's colitis and mucosal immunity. Virchows Arch 463: 637-542, 2013.

19 Nielsen OH, Vainer B and Rask-Madsen J: Non-IBD and noninfectious colitis. Nat Clin Pract Gastroenterol Hepatol 5: 28-39, 2008.

20 Salmo E, El-Dhuwaib Y and Haboubi NY: Histological grading of tumour regression and radiation colitis in locally advanced rectal cancer following neoadjuvant therapy: a critical appraisal. Colorectal Dis 13: 1100-1106, 2011.

21 Rubio CA, Orrego A, Höög A, Porwitz A, Petersson F, Elmberger G, Glaessgen A, Eriksson E, Kanter L, Jaremko G, Egevad L, Laforga J, Liljefors M, Löfdahl B, Norman P, Larsson O, Wanat R, Wejde J, Zickert P, Björk J, Caini S, Palli D and Nesi G: Quantitative assessment of the subepithelial collagen band does not increase the accuracy of diagnosis of collagenous colitis. Am J Clin Pathol 130: 375-381, 2008.

22 Feuerstadt $\mathrm{P}$ and Brandt LJ: Update on colon ischemia: recent insights and advances. Curr Gastroenterol Rep 17: 45-52, 2015.

23 Lee RG: The colitis of Behçet's syndrome Am J Surg Pathol 10: 888-893, 1986.

24 Rubio CA and Nydahl S: "Nonspecific" erosions and ulcers of the colonic mucosa. Dig Dis Sci 39: 821-826, 1994.

25 McKenna BJ and Appelman HD: Dysplasia can be a pain in the gut. Pathology 34: 518-528, 2002.

26 Eaden J, Abrams K, McKay H, Denley H and Mayberry J: Interobserver variation between general and specialist gastrointestinal pathologists when grading dysplasia in ulcerative colitis J Pathol 194: 152-157, 2001.

27 Shih IM, Wang TL, Traverso G, Romans K, Hamilton SR, BenSasson S, Kinzler KW and Vogelstein B: Top-down morphogenesis of colorectal tumors. Proc Natl Acad Sci USA 98: 2640-2645, 2001.

28 Mikami T, Yoshida T, Shiraishi H, Tokuyama W, Motoori T and Okayasu I: Bottom-up cell proliferation with cyclin A and p27Kip1 expression in ulcerative colitis-associated dysplasia. Pathol Int 56: 10-16, 2006.

29 Rubio CA, Befrits R, Jaramillo E, Nesi G and Amorosi A: Villous and serrated adenomatous growth bordering carcinomas in inflammatory bowel disease. Anticancer Res 20: 4761-4764, 2000.

30 Rubio CA: Serrated neoplasias and de novo carcinomas in ulcerative colitis: a histological study in colectomy specimens. J Gastroenterol Hepatol 22: 1024-1031, 2007.

31. Lee LH, Iacucci M, Fort Gasia M, Ghosh S, Panaccione R and Urbanski S: Prevalence and anatomic distribution of serrated and adenomatous lesions in patients with inflammatory bowel disease. Can J Gastroenterol Hepatol 2017: 5490803, 2017.

32 Shen J, Gibson JA, Schulte S, Khurana H, Farraye FA, Levine J, Burakoff R, Cerda S, Qazi T, Hamilton M, Srivastava A and Odze RD: Clinical, pathologic, and outcome study of hyperplastic and sessile serrated polyps in inflammatory bowel disease. Hum Pathol 46: 1548-1556, 2015.

33 Iacucci M, Hassan C, Fort Gasia M, Urbanski S, Gui X, Eksteen B, Eustace G, Kaplan GG and Panaccione R: Serrated adenoma prevalence in inflammatory bowel disease surveillance colonoscopy, and characteristics revealed by chromoendoscopy and virtual chromoendoscopy. Can J Gastroenterol Hepatol 28: 589-594, 2014. 
34 Popp C, Luciana L, Voiosu T, Bastian A, Cioplea M, Micu G, Pop G, Sticlaru L, Bengus A, Voiosu A and Bogdan-Mateescu $\mathrm{R}$ : Expression profile of p53 and p21 in large bowel mucosa as biomarkers of inflammatory-related carcinogenesis in ulcerative colitis. Dis Markers 2016: 3625279, 2016.

35 Kini AT, Thangaraj KR, Simon E, Shivappagowdar A, Thiagarajan D, Abbas S, Ramachandran A and Venkatraman A: Aberrant niche signaling in the etiopathogenesis of ulcerative colitis. Inflamm Bowel Dis 21: 2549-2561, 2015.

36 Noffsinger AE, Miller MA, Cusi MV and Fenoglio-Preiser C: The pattern of cell proliferation in neoplastic and nonneoplastic lesions of ulcerative colitis. Cancer 78: 2307-2312, 1996.

37 You XJ, Bryant PJ, Jurnak F and Holcombe RF: Expression of Wnt pathway components frizzled and disheveled in colon cancer arising in patients with inflammatory bowel disease. Oncol Rep 18: 691-694, 2007.

38 Shenoy AK, Fisher RC, Butterworth EA, Pi L, Chang LJ, Appelman HD, Chang M, Scott EW and Huang EH: Transition from colitis to cancer: high Wnt activity sustains the tumorinitiating potential of colon cancer stem cell precursors. Cancer Res 72: 5091-5100, 2012.
39 You J, Nguyen AV, Albers CG, Lin F and Holcombe RF: Wnt pathway-related gene expression in inflammatory bowel disease. Dig Dis Sci 53: 1013-1019, 2008.

40 Hughes KR, Sablitzky F and Mahida YR: Expression profiling of Wnt family of genes in normal and inflammatory bowel disease primary human intestinal myofibroblasts and normal human colonic crypt epithelial cells. Inflamm Bowel Dis 17: 213-220, 2011.

41 Varner VD and Nelson CM: Cellular and physical mechanisms of branching morphogenesis. Development 141: 2750-2759, 2014. 